\title{
Variation of Oil Introduction Behaviour during Oil-in-Water Emulsion Rolling
}

\author{
Hironobu Nakanishi ${ }^{1,2}$, Kozo Saiki ${ }^{3}$, Tomoko Hirayama ${ }^{2}$ and Takashi Matsuoka ${ }^{2}$ \\ ${ }^{1}$ Mechanical Engineering Research Laboratory, Technical Development Group, Kobe Steel, Ltd., Kobe 651-2271, Japan \\ ${ }^{2}$ Department of Mechanical Engineering, Doshisha University, Kyotanabe 610-0394, Japan \\ ${ }^{3}$ General Administration Department, Technical Development Group, Kobe Steel, Ltd., Kobe 651-2271, Japan
}

\begin{abstract}
In the cold rolling of steel plates and the hot rolling of aluminium plates, an oil-in-water emulsion is used as the rolling oil, both as a coolant and a fire retardant. Understanding the formation mechanisms of the oil film that formed in a roll bite is important for controlling the lubricity and surface quality of the product. This film is formed by introducing oil that spreads on the rolls and strip, which is called "plate-out", and by introducing oil droplets into the inlet zone. However, the effects of these two oil introduction methods on the oil film that formed in the roll bite and the relationship between them have not yet been clarified. In our previous study, oil-film thickness was estimated from the volume of the tracer left on the strip after rolling and the proportion of the volume to that of the oil introduced. The mutual relationships between the volume of the introduced oil and the emulsion particle size, the oil concentration of the emulsion, and rolling velocity were determined. In this study, the effect of plate-out volume on the oil film that formed between the rolls and the strip was investigated by comparing oil-film thickness and plate-out volume. In addition, the behaviour of the introduction of oil droplets for various plate-out volumes was investigated by controlling the supply conditions of the oil-in-water emulsion and the velocity of rolling on a test mill. The effect of plate-out volume was found to decrease and that of oil-droplet introduction was found to increase with an increase in rolling velocity. [doi:10.2320/matertrans.P-M2013807]
\end{abstract}

(Received April 2, 2012; Accepted April 16, 2013; Published July 25, 2013)

Keywords: plate-out, oil droplet, oil-film thickness, rolling process, emulsion, tracer, distribution ratio, oil concentration, particle size, rolling velocity

\section{Introduction}

In the cold rolling of steel plates and the hot rolling of aluminium plates, an oil-in-water $(\mathrm{O} / \mathrm{W})$ emulsion is used as the rolling lubricant, both as a coolant and a fire retardant (Fig. 1). Understanding the mechanisms of oil film formation in the roll bite of steel or aluminium rolling is important for controlling the lubricity and surface quality of the product. This film is formed by introducing an oil that spreads on the rolls and strip, which is called "plate-out", and by introducing oil droplets into the roll bite inlet zone. Subsequently, after the phase switches from $\mathrm{O} / \mathrm{W}$ to $\mathrm{W} / \mathrm{O}$ (Fig. 2), ${ }^{1-3)}$ only oil is introduced to the roll bite. When the oil pressure becomes larger than the yield pressure of the strip in the roll bite, the deformation of the strip starts. The amount of oil introduced into the rolling region (see Fig. 2) is apparently affected not only by the viscosity of the oil but also by its emulsion stability, plate-out property, wettability against metallic surface, and so forth. These phenomena have not been recognized sufficiently, and thus the effects of these two oil introduction mechanisms and the relationship between them must be clarified.

Various methods have been used for estimating the thickness of the oil film that forms in the roll bite. For example, Saeki and Hashimoto used neat oil and estimated the thickness by measuring the oil-drop volume before rolling and the area of the oil film on the strip after rolling. ${ }^{4)}$ Various methods have also been used for emulsion rolling. Some use surface roughness ${ }^{5)}$ or surface glossiness after emulsion rolling. ${ }^{6)}$ In addition, the thickness of the oil film between a glass disk and a metallic roll has been estimated using an interferometer apparatus, ${ }^{7)}$ and the lubricant conditions between rollers have been examined using electrical contact resistance. ${ }^{8)}$ However, unlike the rolling process, these processes are not accompanied by plastic deformation. The use of heavy water including the ${ }^{18} \mathrm{O}$ isotope in the rolling

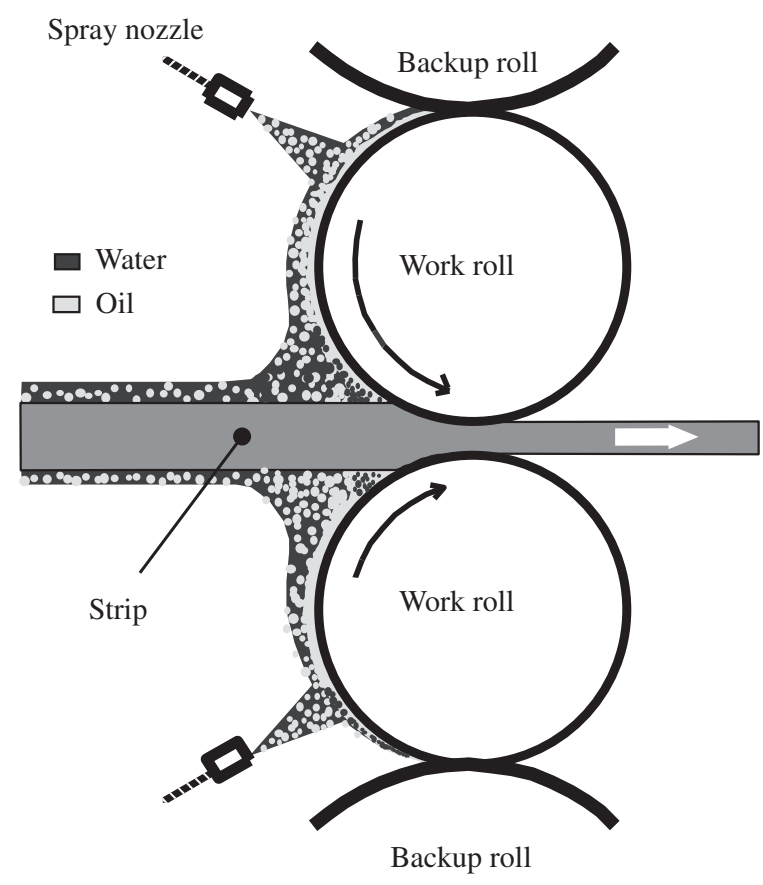

Fig. 1 Rolling mill used for experiments.

process has been studied, ${ }^{9)}$ but oil-film thickness was not measured. Thus, a method of measuring oil-film thickness directly during the emulsion rolling of aluminium or steel has not been adequately established yet. In particular, applicable methods have not been established for processes in which the temperature of the inlet zone reaches or exceeds $400^{\circ} \mathrm{C}$, like aluminium hot-rolling, or for processes in which highly volatile oil is used.

In our previous study, we estimated oil-film thickness from the tracer volume left on the strip after cold rolling and the proportion of that volume to the volume of oil introduced. 


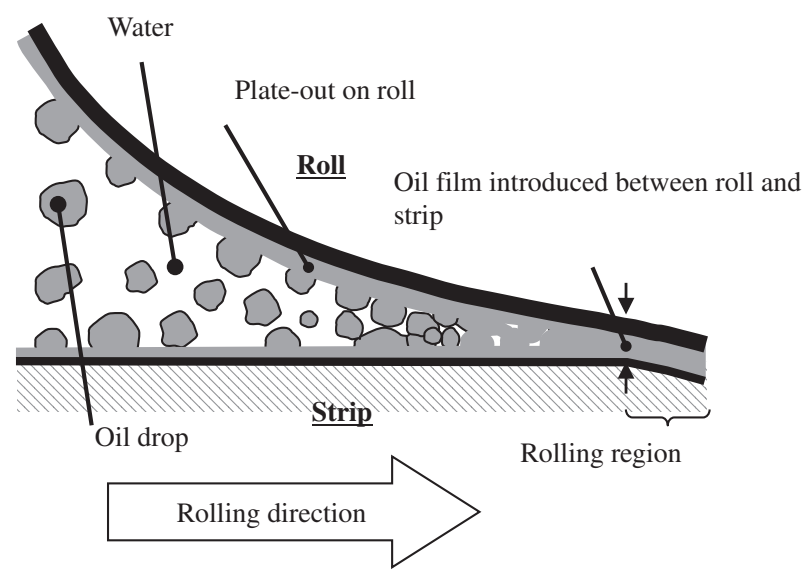

Fig. 2 Inlet zone of rolling region.

Using our results, we determined the mutual relationships between the volumes of the introduced oil and the emulsion particle size, the oil concentration of the emulsion, and rolling velocity. We found that the oil film thickness is less in hot rolling than in cold rolling because the oil viscosity is lower. ${ }^{10)}$

In the study reported here, we investigated the effect of plate-out on oil film formation by comparing oil-film thickness and plate-out volume. In addition, we investigated the behaviour of the introduction of oil droplets by controlling the supply conditions of the $\mathrm{O} / \mathrm{W}$ emulsion and the speed of rolling on a test mill.

\section{Experimental}

\subsection{Materials and apparatus}

The materials and methods used in this experimental research are discussed below. In the tests for the measurement of the thickness of the oil film between a roll and the strip used in rolling, the rolling mill used was two-hi. Each roll had a diameter of $297 \mathrm{~mm}$ and a width of $200 \mathrm{~mm}$. The O/W emulsion, comprising a base oil and a cationic emulsifier, was mixed with a homogenizer. A particle size and counting analyzer using the electrical sensing zone method (measurement error: $\pm 0.6 \mu \mathrm{m}$ ) was used for measuring particle size. The $\mathrm{O} / \mathrm{W}$ emulsion was supplied at $1 \mathrm{~L} / \mathrm{min}$ from a flat-type nozzle to each roll for about $3 \mathrm{~s}$ to stabilize the emulsion supply and roll rotation. An aluminium sheet was then inserted and rolled. The aluminium sheet and rolls were at room temperature.

The rolling test conditions are listed in Table 1. The same rolling mill, rolls and $\mathrm{O} / \mathrm{W}$ emulsion were used to measure plate-out volume. The plate-out on the roll was wiped off using cotton wool. The relationship between plate-out volume and the introduction of oil droplets was investigated using the same rolling mill, rolls and aluminium sheet type. The base oil of the $\mathrm{O} / \mathrm{W}$ emulsion was mineral oil with $2.4 \mathrm{cSt}$ at $40^{\circ} \mathrm{C}$ or $32 \mathrm{cSt}$ at $40^{\circ} \mathrm{C}$, including 3 mass $\%$ oleic acid.

\subsection{Methods}

\subsubsection{Measurement of oil-film thickness}

The thickness of the oil film in the roll bite was measured
Table 1 Test conditions.

\begin{tabular}{cc}
\hline Base oil & $\begin{array}{c}\text { Mineral oil } \\
\left.\text { [viscosity: } 75 \mathrm{mPa} \cdot \mathrm{s} / 20^{\circ} \mathrm{C}\right]\end{array}$ \\
\hline Emulsifying agent & Cationic dispersing agent \\
\hline $\begin{array}{c}\text { Strip temp. } \\
\text { Roll temp. }\end{array}$ & Room temperature \\
\hline Emulsion temp. & $25-30^{\circ} \mathrm{C}$ \\
\hline Roll & SKD61 \\
\hline Strip & Aluminum plate $(\mathrm{A} 1050)$ \\
\hline Spray flow rate & {$\left[{ }^{\mathrm{W}} 80 \times{ }^{\mathrm{L}} 1300 \times{ }^{\mathrm{T}} 2.0\right.$, roughness: Ra $\left.0.2 \mu \mathrm{m}\right]$} \\
\hline Rolling velocity & $1 \mathrm{~L} / \mathrm{min}\left(1 \times 10^{-3} \mathrm{~m}^{3} / \mathrm{min}\right)$ \\
\hline Reduction & $100,300,600,1000 \mathrm{~m} / \mathrm{min}$ \\
\hline
\end{tabular}

using a water-insoluble organometallic compound (metal soap) consisting primarily of metallic elements not included in the roll or strip that served as a tracer. We used this compound because it remained on the sheet after rolling under high-temperature conditions. That is, it did not evaporate or decompose. Moreover, it did not affect emulsion stability or elute from oil to water. Additionally, the precision of the quantitative analysis of the tracer is high. Organometallic components vaporize or decompose above $400^{\circ} \mathrm{C}$. However, the metallic component remains, serving as a tracer for measuring oil-film thickness under hot-rolling conditions. Tracer volume was measured by flameless atomic absorption spectrometry. A $50 \mathrm{~mm} \times 50 \mathrm{~mm}$ sample was cut from the center of the strip, etched for 10 min with 2 mass $\%$ nitric acid, distilled with pure water, and used for quantitative analysis. We can accurately measure oil film thickness which is greater than $1.0 \times 10^{-2} \mu \mathrm{m}$ because of the quantitative precision of the apparatus used and appropriate adjustment of the sample.

The thickness of the oil film on the strip during rolling was measured using oil with 10 mass $\%$ organometallic compound. The size of the particles in the $\mathrm{O} / \mathrm{W}$ emulsion was adjusted for the prescribed conditions. The quantitative analysis and calculation of oil film thickness were carried out using the volume of the tracer that remained on the rolled sheet. The measurement was performed on two areas of the sheet, and the difference between these areas was negligible. The calculated oil film thickness was not the thickness in the roll bite, but that on the rolled strip and other parts on the roll (Fig. 3). It was not always equally distributed because oil wettability is affected by the oil's affinity to the material, surface roughness, rolling conditions, and so forth. If the ratio of the oil film thickness on a strip is known beforehand, the thickness of an oil film in the roll bite can be calculated from the oil film thickness estimated using the tracer volume on the roll. Therefore, we assumed that the distribution ratio of the oil film on the strip to the oil film in the roll bite for the $\mathrm{O} / \mathrm{W}$ emulsion was the same as that for neat oil. We considered this to be a reasonable assumption because the existence of water in the rolling region can be disregarded. The ratio was calculated using the oil-drop rolling test of Saeki and Hashimoto (Fig. 4). ${ }^{4}$ After an oil droplet containing a tracer is placed on the strip, the strip is rolled 
(a) Oil film in roll bite

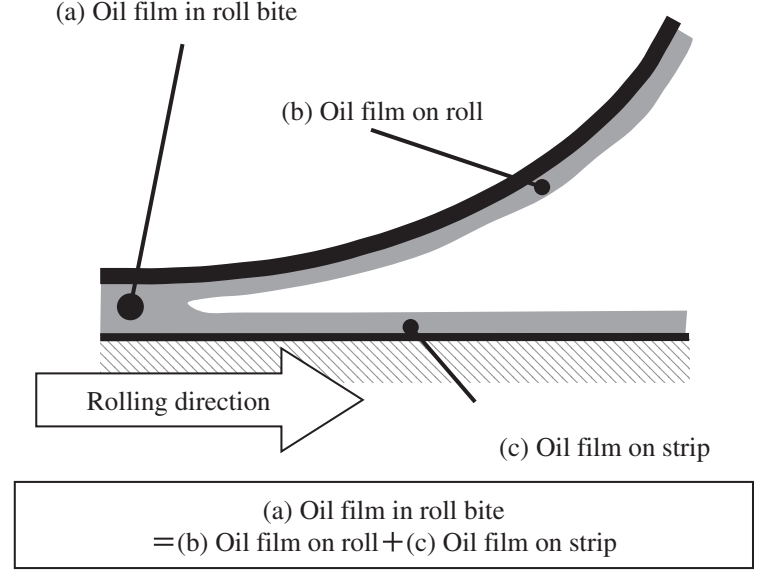

Fig. 3 Outlet zone of rolling region.

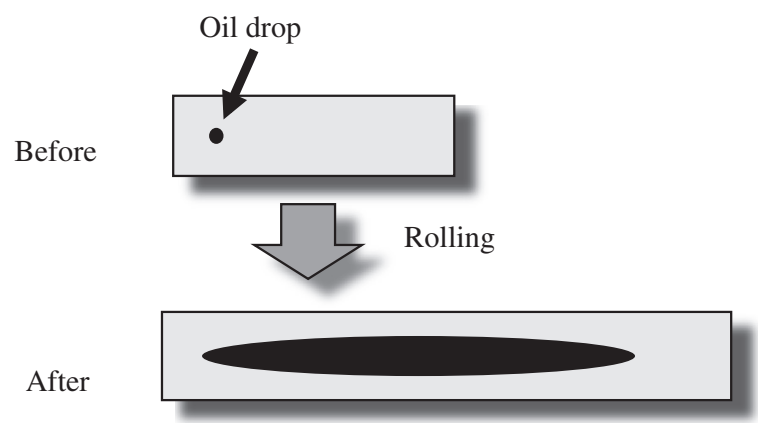

Fig. 4 Droplet method.

under the aforementioned conditions. The thickness of the oil film in the roll bite is estimated by dividing the volume of the oil droplet by the area of the spread oil film. The thickness of the oil film on the strip can be measured with a piece cut from the oil spreading strip area. Two oil film thicknesses can be obtained for a given oil, and the distribution ratio was calculated using both thicknesses.

We thus estimated the thickness of the oil film in the roll bite from the thickness of the oil film on the strip emulsion rolled and the distribution ratio using the oil-drop rolling test (Fig. 5). However, this was the thickness of the oil film in the outlet zone. We assumed that the oil-film thickness at the inlet zone would decrease with increasing rolling surface area and thus adjusted it by applying a multiplier of $1 /(1-r)$, where $r$ is the thickness reduction by rolling. ${ }^{4)}$ In actual rolling, the emulsion is supplied continuously and plate-out forms. In our testing, however, the emulsion was supplied to the rolls for $3 \mathrm{~s}$ before rolling, so that the portion of the strip rolled in the first rotation had excess plate-out. We therefore measured the oil-film thickness from the portion of the strip rolled in the second rotation.

\subsubsection{Measurement of plate-out}

Several methods of measuring plate-out volume have been proposed. ${ }^{11-13)}$ In this study, we measured plate-out volume on a roll using the same rolling mill and rolls as those used for measuring oil-film thickness. Roll rotation was stopped after spraying the emulsion on the rolls for the prescribed time, and the roll surface was masked except for the center of the roll width. The plate-out oil on the unmasked surface was

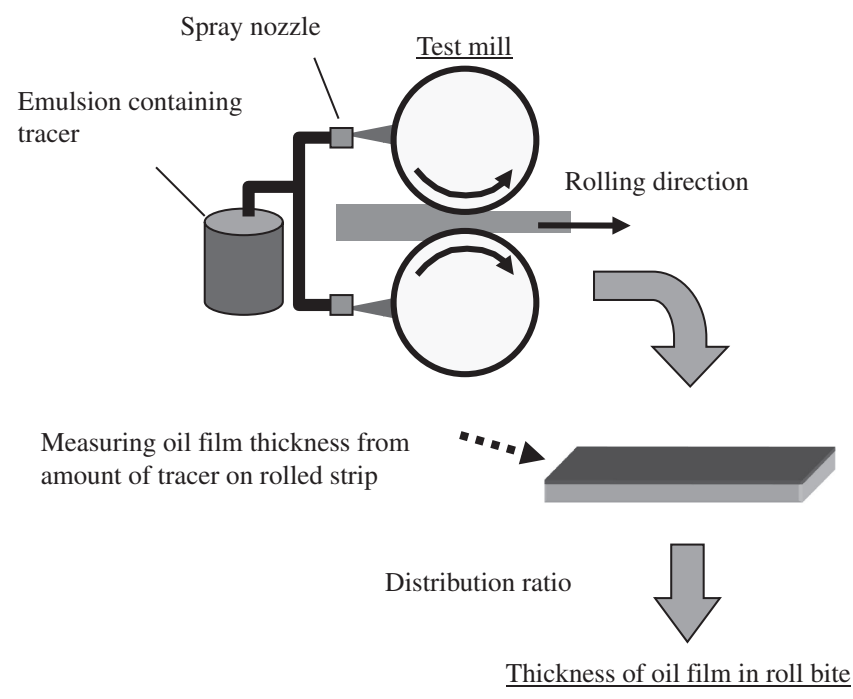

Fig. 5 Flow diagram for tracer method.

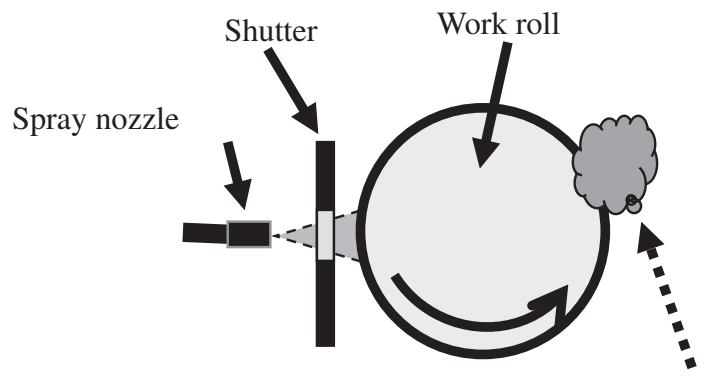

Wiping oil on work roll

Fig. 6 Method of measuring plate-out volume.

wiped off using dried cotton wool with an appropriate amount of hexane. It was then placed in a furnace heated to $150^{\circ} \mathrm{C}$ until their weight stabilized (10 to $15 \mathrm{~min}$ ) to volatilize the hexane and moisture. The difference between the weights before and after wiping was taken as the plate-out volume. Emulsion spray time was controlled using a shutter, as shown in Fig. 6.

\subsubsection{Effect of oil introduction mechanisms}

The differences between the effects of the two oil introduction methods were investigated by using two emulsion supply methods and controlling the supply conditions. The spraying of the emulsion for about $3 \mathrm{~s}$ before rolling caused plate-out to form on the rolls. A strip was then inserted and rolled while spraying the emulsion continuously. On the other hand, the strip was rolled with plate-out only when the emulsion supply was stopped by the shutter. In this way, we were able to identify the effects of plate-out and oil droplet introduction on oil film formation at the inlet of the roll bite.

\section{Results and Discussion}

\subsection{Measurement of oil-film thickness}

\subsubsection{Thickness of oil film on strip}

The thickness of the oil film on the rolled strip was measured and is plotted in Fig. 7. Three rolling tests were 


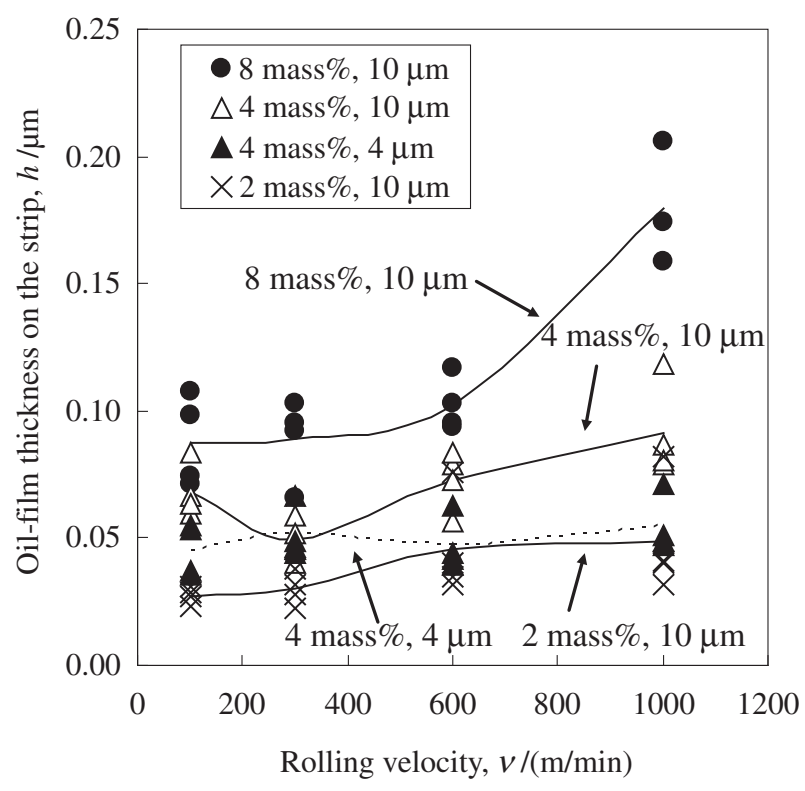

Fig. 7 Thickness of oil film on rolled strip.

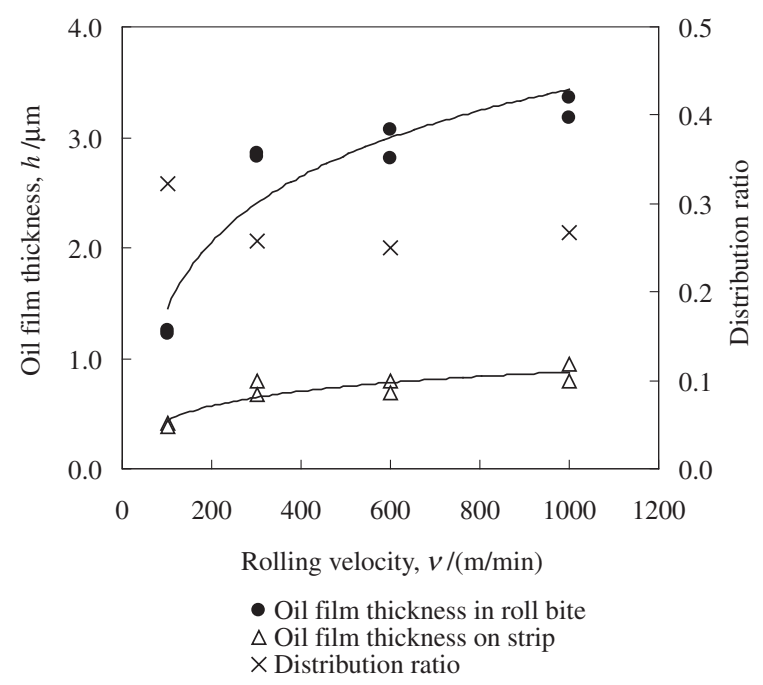

Fig. 8 Thickness of oil film and distribution ratio of neat oil.

carried out under the same experimental conditions (oil concentration and particle size). With a constant particle size $(10 \mu \mathrm{m})$, oil-film thickness increased with an increase in the oil concentration of the emulsion and in rolling velocity. At a constant oil concentration (4 mass \%), oil-film thickness increased with increasing particle size. The difference in the particle size effect was particularly significant at higher rolling velocities.

\subsubsection{Distribution ratio}

The results of the measurement of distribution ratio, the thickness of the oil film on the strip before rolling, and the thickness of the oil film in the roll bite are shown in Fig. 8. Both thicknesses increased with rolling velocity. The distribution ratio of the thickness of the oil film on the strip was about $40 \%$, indicating that the oil introduced into the roll bite was not separated equally after rolling. This may have been due to the difference in oil wettability between the roll and the strip. ${ }^{10)}$

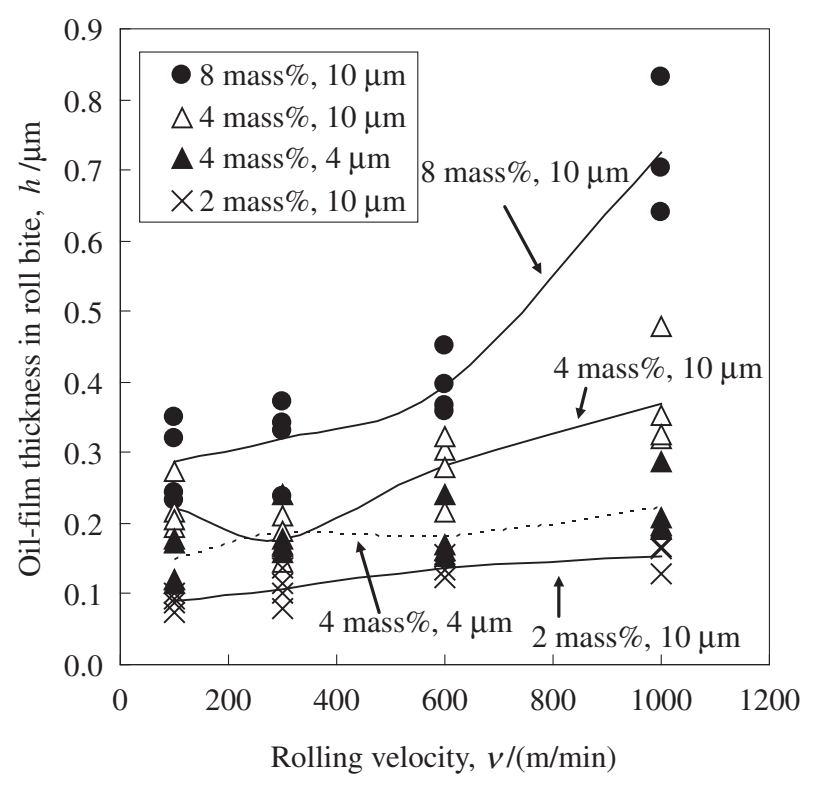

Fig. 9 Thickness of oil film in the roll bite.

\subsubsection{Thickness of oil film in the roll bite}

The results of the thickness of the oil film in the roll bite are shown in Fig. 9. First, the relationship between oil-film thickness and rolling velocity for the same particle size and different oil concentrations is discussed. The oil-film thickness ranged from 0.1 to $1.0 \mu \mathrm{m}$ and increased as the oil concentration of the emulsion increased. The differences between the thicknesses under all conditions increased with increasing rolling velocity. The oil film that forms in the roll bite is thinner at lower rolling velocities according to the hydrodynamic lubrication theory. As a result, the plate-out volume is larger than the volume of oil introduced, and the effect of oil-droplet introduction is smaller. Hence, the difference between the emulsions is smaller. On the other hand, it is more difficult for plate-out to form and the volume of oil introduced in the rolling region is higher at higher rolling velocities. Therefore, the effect of oil-droplet introduction is larger, and the effect of the emulsion conditions is more evident.

Next, the relationship between the thickness of the oil film and rolling velocity for a 4 mass $\% \mathrm{O} / \mathrm{W}$ emulsion is discussed. A larger particle size $(10 \mu \mathrm{m})$ resulted in a thicker oil film, and the difference was greater at higher velocities. This suggests that the use of larger particles facilitates the introduction of oil droplets because larger particles are trapped more effectively on the surface. In addition, lower emulsion stability may cause an increase in plate-out volume. The effect of particle size is smaller at lower velocities, so the plate-out volume may be larger than the amount of oil introduced for the same reason as that in the case of the oil concentration of the emulsion.

\subsection{Volume of plate-out}

Figure 10 shows the results for plate-out thickness obtained for different emulsion concentrations and particle sizes. Plate-out thickness was obtained by dividing the plateout volume by the wiped area. The results for 3-sec emulsion spraying are shown in Figs. 10(a) and 10(b). The results for 
(a)

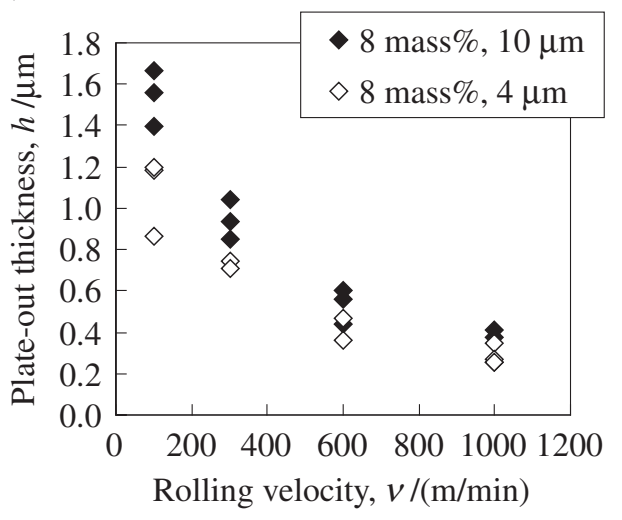

(c)

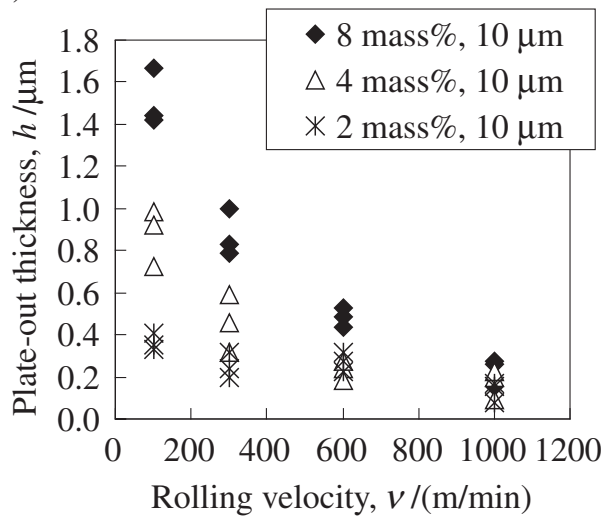

(b)

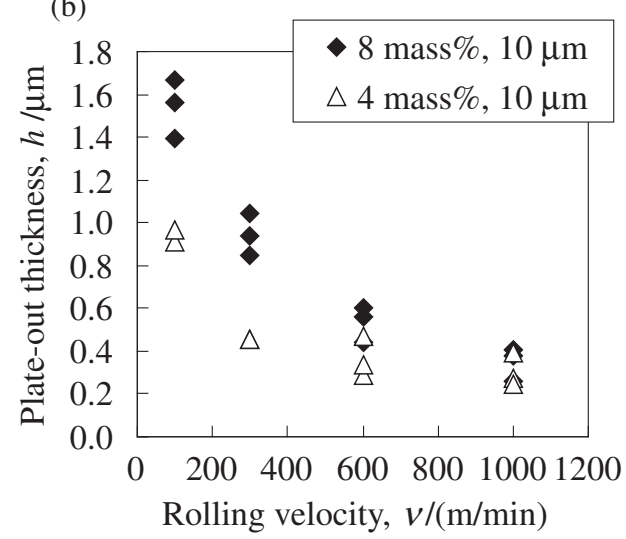

(d)

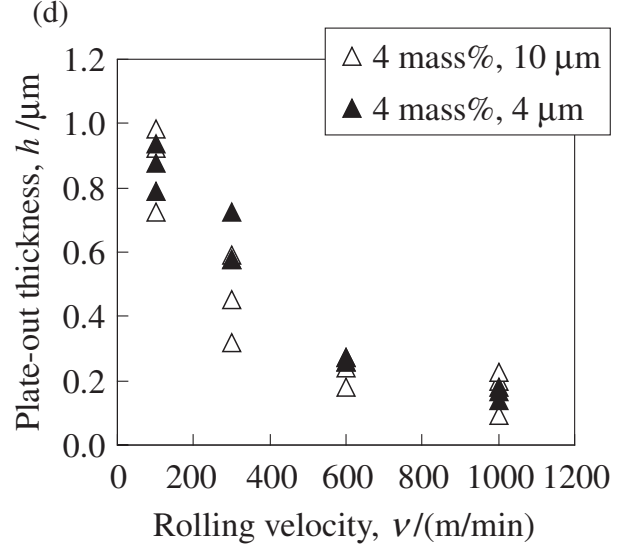

Fig. 10 Plate-out thicknesses under different emulsion conditions.

one-roll rotation are shown in Figs. 10(c) and 10(d). Figures 10(a) and 10(c) show the effect of oil concentration with $10-\mu \mathrm{m}$ particles. Figure 10(b) shows the effect of particle size $(10$ or $4 \mu \mathrm{m})$ with an 8 mass $\%$ emulsion, and Fig. 10(d) shows that with a 4 mass $\%$ emulsion. Plate-out thickness increased with oil concentration [Fig. 10(a)]. This is because the frequency of contact between the roll and the oil droplets increased with increasing number of oil droplets supplied. The differences in plate-out thickness were larger at lower rolling velocities. This suggests that not all of the supplied emulsion remained on the roll; some might have fallen off, and some might have been flung off by the centrifugal force at higher rolling velocities. At lower rolling velocities, the emulsion and oil droplets remained, so plateout formed more easily on the roll. Thus, the effect of oil concentration was greater. Figure 10(b) shows that an increase in particle size increased plate-out thickness. This is because the emulsion is less stable when the particles are larger, leading to the easier binding of oil droplets and better wettability. The supply of the emulsion during one-roll rotation [Figs. 10(c) and $10(\mathrm{~d})$ ] simulates actual rolling, in which the plate-out formed from the emulsion is immediately introduced into the portion of the strip rolled. The results for various oil concentrations at the same particle size [Fig. 10(c)] show the same tendency as that shown in Fig. 10(a): a higher oil concentration leads to an increased plate-out thickness. The difference between the conditions was larger at lower rolling velocities. As shown in Fig. 10(d), an increase in particle size leads to an increase in plate-out
Table 2 Times for one-roll rotation.

\begin{tabular}{cc}
\hline $\begin{array}{c}\text { Rolling velocity } \\
(\mathrm{m} / \mathrm{min})\end{array}$ & $\begin{array}{c}\text { Time for one-roll rotation } \\
(\mathrm{s})\end{array}$ \\
\hline 100 & 0.51 \\
300 & 0.17 \\
600 & 0.08 \\
1000 & 0.05 \\
\hline
\end{tabular}

thickness. However, the differences between the different particle size conditions were smaller than those in Fig. 10(b). This might be due to the lower frequency of collisions and union between oil droplets due to the lower oil concentration. Plate-out thickness decreased with increasing rolling velocity in the one-rotation spray or 3-sec spray. This might be caused by the decrease in the frequency of contact between the roll and the oil droplets because the supplied emulsion has fallen off and been flung off at higher rolling velocities. In addition, it was considered that the decrease in the tendency of the onerotation spray is affected by spraying time for each rolling velocity (Table 2).

The plate-out thickness for the one-rotation spray was slightly smaller than for the 3-sec spray at lower rolling velocities. However, these differences are smaller than those reported in a previous study. ${ }^{13)}$ Plate-out volume may have saturated because of the higher wettability brought about by our emulsions or experimental conditions. 


\subsection{Oil-film thickness at inlet zone and effect of plate-out volume}

The plate-out thicknesses and the thicknesses of the oil film in the roll bite were obtained under the same experimental conditions. However, as mentioned above, it is assumed that the thicknesses of the oil film in the roll bite are formed from the oil film at the inlet zone consisting of plate-out and the introduction of oil droplets. Thus, we concluded that the effect of plate-out in oil formation in the roll bite might be clarified by measuring the thickness of the oil film in the inlet zone. Azushima et al. suggested that the thickness of the oil film that forms in the roll bite can be estimated from the oil film in the inlet zone using the Reynolds equation, which takes into account the effects of temperature and pressure on lubricant viscosity. They experimentally verified the validity of their suggestion. ${ }^{14,15)}$ They used three equations that were also used here:

$$
\begin{aligned}
& \frac{\mathrm{d} P}{\mathrm{~d} h}=-\frac{6 \eta\left(U_{1}+U_{2}\right)}{\tan \theta}\left(\frac{h-h_{1}}{h^{3}}\right), \\
& K \cdot \frac{\mathrm{d}^{2} T}{\mathrm{~d} y^{2}}+\eta\left(\frac{\mathrm{d} u}{\mathrm{~d} y}\right)^{2}=0, \\
& \eta=\eta_{0} \exp \left\{\alpha P+\beta\left(T-T_{0}\right)+\gamma P T\right\},
\end{aligned}
$$

where $U_{1}$ is the strip velocity in the inlet zone, $U_{2}$ is the rolling velocity, $h$ is the oil-film thickness, $h_{1}$ is the thickness of the oil-film in the inlet zone, $\theta$ is the bite angle of rolling, $T$ is the temperature of oil in the roll bite entrance zone, $T_{0}$ is the temperature of the atmosphere, $K$ is the heat conductivity of the lubricant oil, $\eta_{0}$ is the viscosity of the base oil, and $\alpha, \beta$ and $\gamma$ are the temperature and pressure coefficients of viscosity.

From this, we concluded that the thickness of the oil film in the inlet zone could be back-calculated with the oil-film thickness measured in our study and is shown in Fig. 9. Figure 11 shows the results of the back-calculation; the thickness of the oil film in the inlet zone increased with oil concentration and particle size. This tendency is the same as that for the thickness of the oil film in the roll bite, and the thickness increased with increasing rolling velocity, except for the 4 and 8 mass $\%$ emulsions (particle size, $10 \mu \mathrm{m}$ ) at $100 \mathrm{~m} / \mathrm{min}$. This indicates that the thickness of the oil film in the inlet zone may vary with the emulsion and rolling conditions.

The thickness of the oil film in the inlet zone was compared with the plate-out thickness under the corresponding conditions. It was considered that the real volume of the plate-out on the roll in the second rotation is the sum of the oil film from the sprayed emulsion and the residue oil film on the roll after the first rotation. The residue oil on the roll was calculated from the thickness of the oil film on the rolled strip in the first rotation and from the distribution ratio. The results are shown in Fig. 12. The $y$-axis represents the ratio of the plate-out volume to the thickness of the oil film in the inlet zone. If the ratio is greater than 1 , the plate-out volume is sufficient to form an oil film in the roll gap. Conversely, if the ratio is less than 1 , the plate-out volume is insufficient for oil-film formation. This means that oil-droplet introduction is necessary to achieve the measured oil film thickness. The ratio depends on rolling velocity, i.e., it decreases as rolling

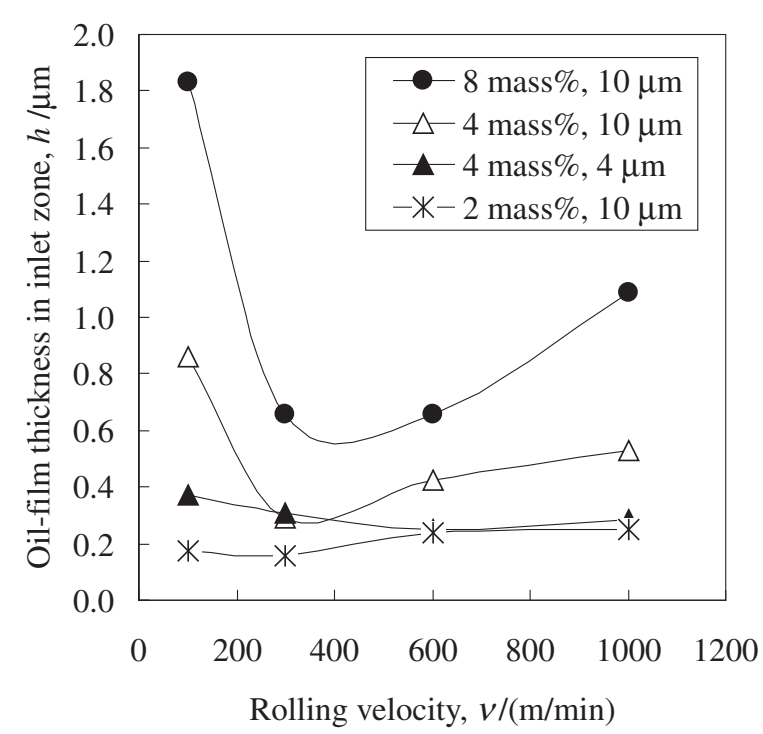

Fig. 11 Thickness of oil film in inlet zone.

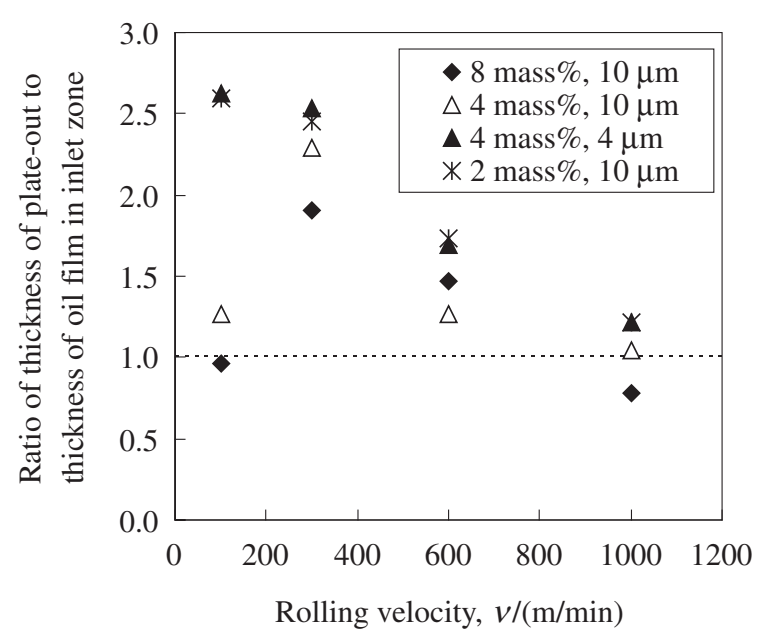

Fig. 12 Ratio of thickness of plate-out to thickness of oil film in inlet zone.

velocity increases (except for 4 and 8 mass $\%$ at $100 \mathrm{~m} / \mathrm{min}$ ). It was less than 1 at higher velocities under certain conditions. This implies that the effect of oil-droplet introduction is greater at higher velocities. The behaviours of the 4 and 8 mass $\%$ emulsions at $100 \mathrm{~m} / \mathrm{min}$ remain to be clarified. Nakahara and coworkers and Zhu et al. observed the behaviour of the oil droplets using an apparatus consisting of a glass disk and a roll. ${ }^{7,16-18)}$ They found that oil pools form in the inlet zone at low rolling velocities and disappear as rolling velocity increases because there is an oil backflow zone in the inlet zone, which makes it more difficult to introduce oil droplets. Film thickness starts increasing again with increasing rolling velocity without oil-pool formation. It was considered that both the oil and water phases are mixed and brought into contact with each other. From this, the same phenomenon may occur in rolling. Oilpool formation and relationship between plate-out and oildroplet introduction may vary with rolling velocity. Because our results were obtained at higher concentrations (4 and 8 mass $\%)$ and a lower velocity $(100 \mathrm{~m} / \mathrm{min})$, the volume of oil supplied may exceed the oil volume used in rolling, and a 


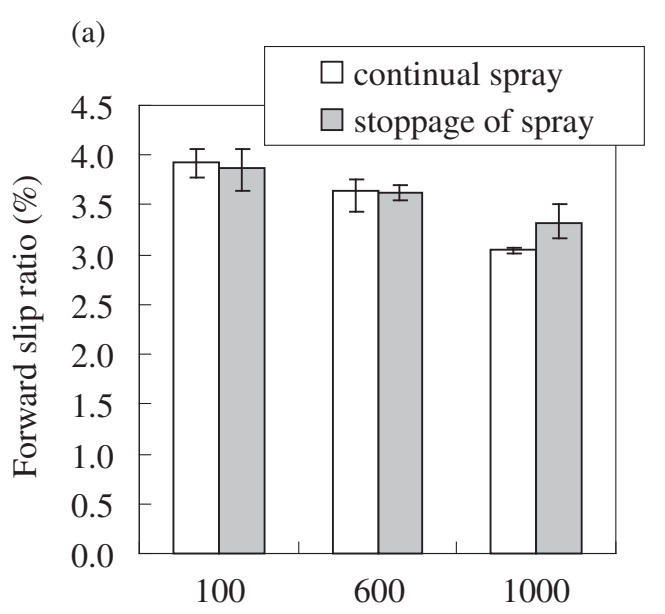

Rolling velocity, $v /(\mathrm{m} / \mathrm{min})$

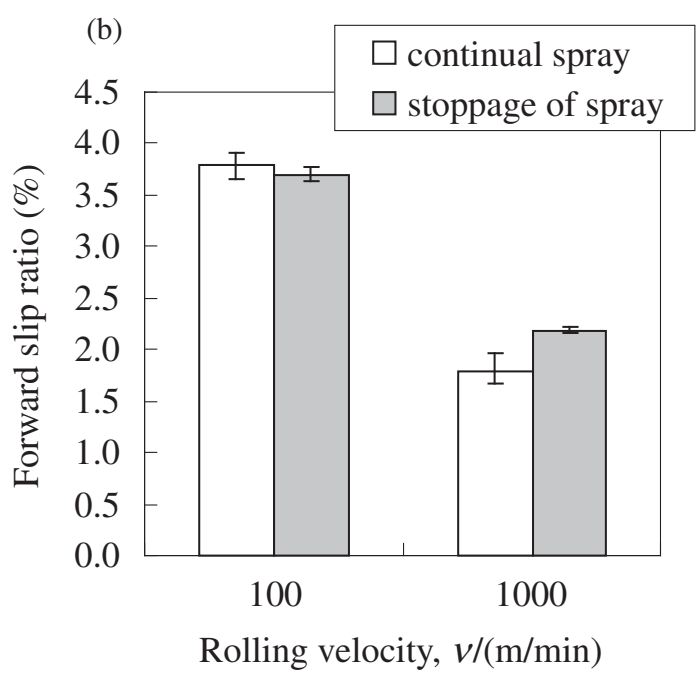

Fig. 13 Effect of spray conditions on forward slip ratio.

oil that is not consumed may remain as an oil pool in the inlet zone. Therefore, it was surmised that a much larger amount of oil is supplied than expected by the oil pool in the inlet zone. On the other hand, the corresponding plate-out volume results from the innate emulsion. As a result, the ratio may decrease.

In this work, we focused on the phenomenon that the ratios of thickness of plate-out to thickness of oil film in inlet zone become less than 1 at higher rolling velocities and investigated the relationship between rolling velocity and emulsion supply conditions to verify the hypothesis that the plate-out volume is insufficient for oil-film formation, and oil-droplet introduction cannot be neglected at higher rolling velocities.

\subsection{Effect of two oil-introduction mechanisms}

As mentioned above, the variation in the relationship between the two oil-introduction methods was investigated using two emulsion supply methods. In one, the emulsion was sprayed continuously while the sheet was being rolled. In the other, emulsion supply was stopped immediately before a sheet was inserted, which meant that the strip was rolled with only the plate-out. Two mineral oil viscosities were used. The results are shown in Figs. 13(a) and 13(b). Regardless of mineral oil viscosity, forward slip ratio decreased as rolling velocity increased. In particular, at higher rolling velocities with higher viscosity, the ratio was lower owing to the hydrodynamic lubrication effect.

The forward slip ratios at a rolling velocity below 600 $\mathrm{m} / \mathrm{min}$ were not significantly different between the two supply methods. At $1000 \mathrm{~m} / \mathrm{min}$, however, the forward slip ratio was higher for the stoppage method. At lower velocities, the plate-out volume on the roll was sufficient so that the effect of oil-droplet introduction was not large. Reversely, at higher rolling velocities, the plate-out volume was lower, so the amount of oil droplets introduced into the rolling region was higher. As a result, the plate-out volume was insufficient and the effect of oil-droplet introduction was significant. This supports the hypothesis that oil-pool formation and the relationship between plate-out and oil-droplet introduction may vary with rolling velocity.

\section{Conclusions}

We experimentally estimated the thickness of the oil film that forms in a roll bite and plate-out volume in oil-water emulsion rolling. The thickness of the film in the inlet zone of the rolling region was calculated from the thickness of the oil film in the roll bite and compared with the plate-out volume to investigate the mechanism of oil film formation between a roll and a strip. We obtained several results of particular importance as follows.

(1) Oil-film thickness increased with the oil concentration of the emulsion, particle size and rolling velocity. The differences in thickness between the conditions depended on the rolling velocity.

(2) Plate-out volume increased with increasing oil concentration and particle size and decreased with increasing rolling velocity. The difference in volume between the emulsion conditions was greater at lower rolling velocities.

(3) The thickness of the oil film in the inlet zone was calculated from the thickness of the oil film that formed in the roll bite. The thickness of the oil film in the inlet zone increased with oil concentration, particle size and rolling velocity.

(4) The relationship between plate-out volume and the thickness of the oil film in the inlet zone varied with rolling velocity. The effect of oil-droplet introduction was greater at higher velocities.

In this study, we used an aluminium sheet in cold rolling. If the material, surface roughness, temperature and other test conditions are changed, the behaviour of oil introduction may change because the affinity between the oil and the strip changes. However, these results show that it is important to understand not only the properties of the additives and plateout but also the behaviour of oil-pool formation and oildroplet introduction to effectively control the lubricity and surface quality of the rolled product in actual $\mathrm{O} / \mathrm{W}$ emulsion rolling. 


\section{REFERENCES}

1) Y. Kimura and K. Okada: Proc. JSLE. Int. Trib. Conf., (Tokyo, Japan, 1985) pp. 937-942.

2) Y. Kimura and K. Okada: J. Jpn. Soc. Tribologists 34 (1989) 200-207.

3) K. Nakajima, Y. Shibata and Y. Uebori: Proc. 1979 Japanese Spring Conf. Technol. Plasticity, (1979) p. 379.

4) K. Saeki and Y. Hashimoto: J. JSTP 8 (1967) 34-42.

5) S. Sakai, Y. Saito, S. Okamoto and K. Kato: J. JSTP 19 (1978) 972 979.

6) A. Azushima, K. Noro and Y. Iyanagi: J. Jpn. Soc. Tribologists 34 (1989) 879-886.

7) T. Nakahara, T. Makino and K. Kyogoku: Trans. ASME J. Trib. 110 (1988) 348-353

8) Y. Kimura and K. Okada: J. Jpn. Soc. Tribologists 34 (1985) 274-281.
9) R. A. Reich, J. M. Epp and R. P. Festa: Lubr. Eng. 50 (1994) 31.

10) H. Nakanishi and K. Saeki: J. Jpn. Soc. Tribologists 55 (2010) 745752 .

11) T. Mase, T. Kono and H. Yamamoto: Proc. 28th Japanese Joint Conf. Technol. Plasticity, (1977) p. 114.

12) T. Mase, T. Kono and H. Yamamoto: Tetsu-to-Hagane 64 (1978) 250 .

13) M. Shirata and K. Sakai: J. Jpn. Soc. Lubr. Eng. 27 (1982) 594-599.

14) A. Azushima and K. Kitamura: Proc. 1986 Japanese Spring Conf. Technol. Plasticity, (1986) pp. 151-154.

15) A. Azushima and K. Kitamura: J. JSTP 19 (1978) 958-965.

16) T. Nakahara, S. Shiokawa and K. Kyogoku: J. Jpn. Soc. Tribologists 35 (1990) 907-913.

17) T. Nakahara: J. Jpn. Soc. Tribologists 40 (1995) 644-649.

18) D. Zhu, G. Biresaw, S. J. Clark and T. J. Kasun: Trans. ASME J. Trib. 116 (1994) 310-320. 